\title{
Quality of Life Predictors in Breastfeeding Mothers Referred to Health Centers in Iran
}

\author{
Mahin Kamalifard ${ }^{1}$, Mojgan Mirghafourvand ${ }^{2}$, Fatemeh Ranjbar ${ }^{3}$, Nasrin Gordani ${ }^{*}$
}

\begin{abstract}
Objectives: Considering the importance of breastfeeding and positive role of the quality of life (QoL) of mothers in it, we intended to investigate QoL predictors.

Materials and Methods: This cross-sectional study was conducted on 547 eligible breastfeeding mothers with infants, aged between 2 and 6 months, referred to health centers in Falavarjan, a city in Iran. Participants were selected randomly. The socio-demographic questionnaire and QOL Inventory of the World Health Organization (WHO) were completed through interview. The multivariate linear regression analysis was carried out to investigate the relationship of QoL with socio-demographic characteristics.

Results: The mean score (standard deviation) of QoL was 67.6 (13.7) from a range between 0 and 100. According to the multivariate linear regression analysis, the variables of mother's age, spouse's age and job, economic status, gestational age at delivery, gravidity, tendency towards pregnancy, breastfeeding history, and breastfeeding training had relationship with QoL.

Conclusion: Considering that the effects of socio-demographic factors on QOL in breastfeeding mothers can be moderated, it seems that the QOL of such mothers can be improved through extensive planning and supportive strategies by family and society.

Keywords: Breastfeeding, Quality of life, Demographic factors
\end{abstract}

\section{Introduction}

Quality of life (QoL) is a multidimensional and complex concept, and also a comprehensive and flexible process that encompasses all aspects of people's life. It not only meets essential needs, but also includes factors that cause self-actualization $(1,2)$. In other words, QoL originates from people's satisfaction or dissatisfaction with different aspects of life, which are important to them. It includes health, occupational, economic, psychological-mental, and family areas, and is an important criterion for measuring health care quality (3).

The significance of breastfeeding is to the extent that it has been extensively highlighted in Islam (4). Breast milk provides all energy and nutrients that the infant needs for the first 6 months of life (5). Breastfeeding protects the infant from respiratory diseases, allergies, gastroenteritis and malnutrition (6). It also decreases the risk of overweight and obesity, and associated complications during childhood and adolescence (7). Moreover, breastfeeding decreases the risk of breast and ovarian cancers in mothers, facilitates postpartum weight loss, and controls maternal bleeding after delivery (8). Unfortunately, despite these advantages, only $41.3 \%$ of mothers continue breastfeeding for up to one year. On the other hand, $9.7 \%$ of mothers do not breastfeed at all (9).

Successful breastfeeding depends on physiological and psychological factors (10). Since QoL includes physical and psychological health factors, social relationship and the living conditions, it may affect breastfeeding. Zubaran and Foresti in a study in the southern part of Brazil also reported this relationship (11). In a study, Chen et al compared the relationship of health with QoL in mothers, who adopted different breastfeeding patterns, and showed that mothers who continued breastfeeding for 6 months or more obtained significantly higher QoL score (12). Moreover, a study in Iran by Alijanpoor and Bahadoran showed that QoL in breastfeeding mothers was higher than in non-breastfeeding mothers (13).

Regarding the importance of QoL in breastfeeding, we explored valid scientific databases. Few studies have been done on QoL predictors during breastfeeding (13), so we intended to assess the socio-demographic predictors of QoL in breastfeeding mothers. On the other hand, as midwives, who are responsible for providing breastfeeding healthcare and counseling (14), we aimed to improve health and QoL of mothers, as well as breastfeeding rate through extensive planning and supportive strategies by family and society.

\section{Materials and Methods}

Study Design and Participants

This cross-sectional study was conducted from June to November 2015 on 547 breastfeeding mothers in the health centers in Falavarjan, a city in Isfahan province, Iran. 
The inclusion criteria included the following: mothers with 2- to 6-month-old infants, mothers with infants born at term in the gestational age, lack of any disorder in the infant's mouth or tongue, which could influence his/ her feeding from mother's breast (such as glossitis, short frenulum and cleft palate), lack of neonatal hospitalization during infancy, lack of distance between the mother and neonate in the early days after birth, lack of self-reported maternal mental disorders requiring treatment, Iranian nationality and having a phone number. The exclusion criteria also included the following: having breastfeeding contraindications such as drug and alcohol abuse, having galactosemic infants, women with HIV, women with active untreated tuberculosis, women receiving breast cancer treatment, women with hepatitis B and nonvaccinated infants and women with breast herpes. In addition, women who were not willing to participate in this research were excluded.

According to the findings reported by Alijanpoor and Bahadoran and considering the following indices, the sample size was calculated to be 496 with mean $=82.1$; standard deviation $=13.1 ; \mathrm{CI}=95 \%$; power $=90 \%$; and precision $(\mathrm{d})=0.02$ (around the mean value). Considering a possible loss of $10 \%$, the final sample size was estimated to be 547 .

\section{Sampling}

The sampling was performed in health centers in Falavarjan. This city embraces 12 urban health centers, and samples were collected from these health centers. The mothers had files in health centers. To carry out the sampling, first a list of breastfeeding women with 2 to 6-month-old infants, who met the inclusion criteria, was extracted from the files in health centers. The women were listed by numbers and samples were selected randomly by Randomizer software. The samples were invited to attend the briefing session through phone calls. The written informed consent was obtained from women, who were willing to take part in this research after participating in the briefing session and receiving explanations about the research objectives and methods.

\section{Data Collection Tools}

Data were collected using the following 2 questionnaires: the socio-demographic characteristics questionnaire and the World Health Organization's Quality of Life scale (WHOQoL-BREF). The questionnaires were completed through interview.

The socio-demographic characteristics questionnaire included 22 questions about the age, job, education, and obstetric and breastfeeding characteristics.

The WHOQoL-BREF, which is used to assess QoL contains 24 questions covering the following 4 dimensions: physical health (questions No. 3, 4, 10, 15, 16, 17, 18), psychological health (questions No. 5, 6, 7, $11,19,26)$, social relations (questions No. 20, 21, 22), and living environment (questions No. 8, 9, 12, 13, 14, $23,24,25)$. There are also 2 questions (No. 1,2) that are not associated with these dimensions. The score of each statement varies between 1 and 5. One refers to "never" and five refers to "completely satisfied". Questions No. 3 and 4 are scored in reverse. The scores range from 0 to 100 for this questionnaire. Reliability and validity of this scale were also assessed in 2007 by Nejat et al. In this research, reliability of the scale was confirmed for all dimensions of QoL with Cronbach a coefficient of over 0.7.

\section{Data Analysis}

Statistical analysis was performed by SPSS version 21.0. Descriptive statistics including frequency, percent, mean and standard deviation were used to describe QoL. To analyze the relationship of QoL with each sociodemographic factor, bivariate statistical tests, including independent $t$ test and one-way analysis of variance (ANOVA) were used. Those socio-demographic variables that had relationship with QoL with $P<0.2$ were included in the multivariate linear regression model with a backward strategy. Before the conduction of multivariate analysis, the regression assumptions including normality, residuals, homogeneity of variance, collinearity of outliers, and independence of residuals were investigated.

\section{Results}

Results obtained from socio-demographic characteristics questionnaire were presented in Table 1. The mean score (standard deviation) of QoL was 67.7 (13.7) from a range between 0 and 100 .

The relationship between socio-demographic characteristics and QoL based on bivariate test was shown in Table 2.

According to multivariate linear regression model with a backward strategy, the variables of age, spouse's age, spouse's job, spouse's education, economic status, gestational age at delivery, gravidity, tendency towards pregnancy, history of breastfeeding, and receiving breastfeeding training were predictors of QoL and accounted for $28.2 \%$ of the variance of QoL score. These results were presented in Table 3 .

\section{Discussion}

Results of this study showed that the mean score of QoL in breastfeeding mothers in this study was higher than average. In addition, following variables were among QoL predictors in breastfeeding mothers: age, spouse's age, spouse's job, spouse's education, economic status, gestational age at delivery, parity, tendency to pregnancy, history of breastfeeding, and receiving breastfeeding training.

With respect to the mean QoL score of breastfeeding mothers, findings of the present study are almost consistent with those of a study done by Ghodsbin et al, conducted in Shiraz, Iran in 2012. In their study, the QoL 
Table 1. SocioDemographic Characteristics of Participants $(n=547)$

\begin{tabular}{|c|c|}
\hline Characteristic & No. (\%) \\
\hline \multicolumn{2}{|l|}{ Age } \\
\hline $15-25$ & $219(40.0)$ \\
\hline $25-35$ & $196(35.8)$ \\
\hline$>35$ & $132(24.2)$ \\
\hline \multicolumn{2}{|l|}{ Job } \\
\hline Housewife & $489(89.4)$ \\
\hline Employed & $58(10.6)$ \\
\hline \multicolumn{2}{|l|}{ Education } \\
\hline Illiterate and primary school & $54(9.9)$ \\
\hline Secondary school & $63(11.5)$ \\
\hline High school & $26(4.8)$ \\
\hline Diploma & $249(45.5)$ \\
\hline University & $155(28.3)$ \\
\hline \multicolumn{2}{|l|}{ Husband's age } \\
\hline $20-25$ & 54 (9.9) \\
\hline $25-30$ & $202(36.9)$ \\
\hline $30-35$ & $152(29.1)$ \\
\hline$>35$ & $132(24.1)$ \\
\hline \multicolumn{2}{|l|}{ Husband's job } \\
\hline Unemployed & $27(4.9)$ \\
\hline Worker & $170(31.3)$ \\
\hline Employee & 98 (17.9) \\
\hline Shop keeper & $25(4.6)$ \\
\hline Freelancer & $187(34.2)$ \\
\hline Others & $40(7.3)$ \\
\hline \multicolumn{2}{|l|}{ Husband's education } \\
\hline Illiterate and primary school & $47(8.6)$ \\
\hline Secondary school & $83(15.2)$ \\
\hline High school & $44(8)$ \\
\hline Diploma & $239(43.7)$ \\
\hline University & $134(24.5)$ \\
\hline \multicolumn{2}{|l|}{ Economic condition } \\
\hline Satisfactory & $192(35.1)$ \\
\hline Almost satisfactory & $309(56.5)$ \\
\hline Unsatisfactory & $46(8.4)$ \\
\hline \multicolumn{2}{|l|}{ Number of pregnancy } \\
\hline 1 & $283(51.7)$ \\
\hline 2 & 158 (28.9) \\
\hline 3 & $66(12.1)$ \\
\hline 4 and more & $40(7.3)$ \\
\hline \multicolumn{2}{|l|}{ Number of labors } \\
\hline 1 & $298(54.5)$ \\
\hline 2 & 169 (30.9) \\
\hline 3 & $55(10.1)$ \\
\hline 4 and more & $25(4.6)$ \\
\hline Infant age difference with previous child & $5.30(3.08)^{*}$ \\
\hline \multicolumn{2}{|l|}{ Pregnancy age at the time of labor } \\
\hline$<34$ & $13(2.4)$ \\
\hline $34-40$ & $495(91.5)$ \\
\hline$>40$ & $33(6.1)$ \\
\hline \multicolumn{2}{|l|}{ Tendency for pregnancy } \\
\hline Wanted & 435 (79.5) \\
\hline
\end{tabular}

\section{Table 1. Continued}

\begin{tabular}{|c|c|}
\hline Unwanted & $112(20.5)$ \\
\hline \multicolumn{2}{|l|}{ Method of pregnancy } \\
\hline Natural & $513(93.8)$ \\
\hline Infertility treatment & $34(6.2)$ \\
\hline \multicolumn{2}{|l|}{ Interest in infant's sex } \\
\hline Wanted & $354(64.7)$ \\
\hline Unwanted & $193(35.3)$ \\
\hline \multicolumn{2}{|l|}{ Infant's sex } \\
\hline Male & $278(51)$ \\
\hline Female & $267(49)$ \\
\hline Infant's age & $3.98(1.51)^{*}$ \\
\hline \multicolumn{2}{|l|}{ History of breastfeeding } \\
\hline Yes & $244(44.6)$ \\
\hline No & $303(55.4)$ \\
\hline Average duration of previous breastfeeding period & $20.79(5.05)^{*}$ \\
\hline \multicolumn{2}{|l|}{ Use of lactation enhancement medicine } \\
\hline Yes & $110(20.1)$ \\
\hline No & 437 (79.9) \\
\hline \multicolumn{2}{|l|}{ Use of nutrients } \\
\hline Yes & $138(25.2)$ \\
\hline No & 409 (74.8) \\
\hline \multicolumn{2}{|l|}{ Receiving breastfeeding training } \\
\hline Yes & $471(86.3)$ \\
\hline No & 75 (13.7) \\
\hline \multicolumn{2}{|l|}{ Breastfeeding trainer } \\
\hline Physician & $29(6)$ \\
\hline Obstetrician or nurse & $452(94)$ \\
\hline
\end{tabular}

* Numbers indicate mean (standard deviation) values.

score was higher than the average, too (15). Moreover, the results of present study are consistent with the results of the study by Mirzayi et al, which was conducted in Tabriz, Iran in 2014. This consistency may be due to the similarity between the sample size and some socio-demographic factors among the participants (16).

In this study, the mean QoL score of breastfeeding mothers had an inverse correlation with the age of mother and her spouse. In terms of age, the highest mean score of QoL was observed among women aged 15 to 25 years and their spouses aged 20 to 25 years. This finding is consistent with the finding of the study conducted by Baghaei et al on QoL predictors among dialysis patients, that QoL has an inverse correlation with age (17). Moreover, it is consistent with the study by Akýn et al on women of childbearing age, who were in the first year postpartum (18). The inverse relationship of QoL with age may be justified by putting that physical strength reduces with aging, resulting in lower QoL. This reduction in QoL of women has a direct negative impact on breastfeeding. With respect to men, this loss of physical strength reduces their functionality and income, making them incapable of providing for their families sufficiently, which indirectly leads to a reduction in QoL of breastfeeding mothers $(19,20)$. 
Table 2. Relationship Between Socio-demographic Characteristics and Quality of Life in Breastfeeding Mothers Referred to Health Centers in Falavarjan, Iran ( $n=547)$

\begin{tabular}{|c|c|c|}
\hline Characteristic & Mean (SD)* & $\boldsymbol{P}$ \\
\hline Age & & $<0.001$ \\
\hline $15-25$ & 69.4(12.9) & \\
\hline $25-35$ & $68.5(14.5)$ & \\
\hline$>35$ & $63.5(12.9)$ & \\
\hline Job & & $<0.001$ \\
\hline Housewife & $67.2(13.7)$ & \\
\hline Employed & $71.9(12.9)$ & \\
\hline Education & & $<0.001$ \\
\hline Illiterate and primary school & $59.5(13.1)$ & \\
\hline Secondary school & $65.0(14.0)$ & \\
\hline High school & $62.1(16.1)$ & \\
\hline Diploma & $68.6(13.1)$ & \\
\hline University & $71.1(12.7)$ & \\
\hline Husband's age & & $<0.001$ \\
\hline $20-25$ & $71.4(12.1)$ & \\
\hline $25-30$ & $68.8(13.6)$ & \\
\hline $30-35$ & $68.8(12.9)$ & \\
\hline$>35$ & $63.8(14.6)$ & \\
\hline Husband's job & & $<0.001$ \\
\hline Unemployed & $54.1(12.4)$ & \\
\hline Worker & $65.7(12.0)$ & \\
\hline Employee & $70.6(13.6)$ & \\
\hline Shop keeper & $69.1(15.4)$ & \\
\hline Freelancer & $68.7(13.7)$ & \\
\hline Others & $72.5(13.9)$ & \\
\hline Husband's education & & $<0.001$ \\
\hline Illiterate and primary school & $59.5(13.0)$ & \\
\hline Secondary school & $62.2(13.2)$ & \\
\hline High school & $63.6(10.7)$ & \\
\hline Diploma & $70.4(13.2)$ & \\
\hline University & $70.4(13.7)$ & \\
\hline Economic condition & & $<0.001$ \\
\hline Satisfactory & $72.9(12.8)$ & \\
\hline Almost satisfactory & $67.2(12.6)$ & \\
\hline Unsatisfactory & $52.2(12.4)$ & \\
\hline Number of pregnancy & & $<0.001$ \\
\hline 1 & $70.1(13.0)$ & \\
\hline 2 & $66.1(14.6)$ & \\
\hline 3 & $65.4(11.5)$ & \\
\hline 4 and more & $60.7(14.2)$ & \\
\hline Number of labors & & $<0.001$ \\
\hline 1 & $69.9(12.8)$ & \\
\hline 2 & $66.2(14.0)$ & \\
\hline 3 & $65.0(13.5)$ & \\
\hline 4 and more & $57.2(14.8)$ & \\
\hline Infant age difference with previous child & $65.0(13.9)$ & 0.010 \\
\hline Pregnancy age at the time of labor & & 0.008 \\
\hline$<34$ & $66.6(10.3)$ & \\
\hline $34-40$ & $67.5(13.8)$ & \\
\hline$>40$ & $71.3(13.7)$ & \\
\hline
\end{tabular}

\section{Table 2. Continued}

\begin{tabular}{|c|c|c|}
\hline Tendency for pregnancy & & $<0.001$ \\
\hline Wanted & $69.5(13.3)$ & \\
\hline Unwanted & 71.9 (12.9) & \\
\hline Method of pregnancy & & 0.112 \\
\hline Natural & $67.9(13.6)$ & \\
\hline Infertility treatment & $64.1(14.1)$ & \\
\hline Interest in infant's sex & & 0.012 \\
\hline Wanted & $68.8(13.1)$ & \\
\hline Unwanted & $65.6(14.5)$ & \\
\hline Infant's sex & & 0.243 \\
\hline Male & $67.0(14.0)$ & \\
\hline Female & $68.4(13.4)$ & \\
\hline Infant's age & $67.7(13.7)$ & 0.048 \\
\hline History of breastfeeding & & 0.021 \\
\hline Yes & $66.2(14.2)$ & \\
\hline No & $68.9(13.2)$ & \\
\hline $\begin{array}{l}\text { Average duration of previous breastfeeding } \\
\text { period }\end{array}$ & $65.4(14.0)$ & 0.463 \\
\hline Use of lactation enhancement medicine & & 0.011 \\
\hline Yes & $64.7(12.7)$ & \\
\hline No & $68.4(13.8)$ & \\
\hline Use of nutrients & & 0.416 \\
\hline Yes & $66.9(12.8)$ & \\
\hline No & $68.0(14.0)$ & \\
\hline Receiving breastfeeding training & & 0.019 \\
\hline Yes & $68.2(13.5)$ & \\
\hline No & $64.2(14.4)$ & \\
\hline Breastfeeding trainer & & 0.010 \\
\hline Physician & $68.1(13.4)$ & \\
\hline Obstetrician or nurse & $68.0(13.5)$ & \\
\hline
\end{tabular}

*Standard deviation

In addition, this study showed that the spouse's education has a direct correlation with the mean score of QoL in breastfeeding mothers. This finding is consistent with the finding of the study by Akýn et al conducted on women in 2009 (18). This study is also consistent with the studies conducted by Lopes et al and Pakpour et al, in which there is a direct correlation between educational level and QoL $(21,22)$. In other words, educational level and subsequently the income of the spouse have a direct correlation with the improvement of QoL of family members, including the mother, through provision of better living conditions $(21,22)$.

In this study, QoL had a direct relationship with economic status, which is consistent with the findings of the study by Akýn et al (18). Favorable economic status brings welfare and medical and care facilities to breastfeeding mothers and improves their QoL (23).

The present study revealed that people with intended pregnancy had relatively higher QoL than those with unintended pregnancy. This is probably because individuals with intended and successful term pregnancy 
Table 3. Predictive Factors of Quality of Life in Breastfeeding Mothers Referred to Health Centers in Falavarjan, Iran

\begin{tabular}{|c|c|c|}
\hline Variable & $\mathrm{B}(\mathrm{CI})$ & $P$ \\
\hline \multicolumn{3}{|l|}{ Age } \\
\hline $15-25$ & 0 & 0 \\
\hline $25-35$ & $0.6(-2.1$ to 3.3$)$ & 0.673 \\
\hline$>35$ & $-2.5(-6.4$ to 1.3$)$ & 0.196 \\
\hline \multicolumn{3}{|l|}{ Husband's age } \\
\hline $25-30$ & 0 & 0 \\
\hline $20-25$ & 5.7 (2.0 to 9.5$)$ & 0.003 \\
\hline $30-35$ & $0.0(-2.9$ to 2.8$)$ & 0.964 \\
\hline$>35$ & $0.1(-3.9$ to 4.2$)$ & 0.931 \\
\hline \multicolumn{3}{|l|}{ Husband's job } \\
\hline Freelancer & 0 & 0 \\
\hline Unemployed & $4.4(-9.8$ to 0.9$)$ & 0.109 \\
\hline Worker & $-1.7(-4.2$ to 0.8$)$ & 0.187 \\
\hline Employee & $1.5(-1.7$ to 4.8$)$ & 0.353 \\
\hline Shop keeper & $-2.7(-7.8$ to 2.3$)$ & 0.284 \\
\hline Others & 4.2 (0.1 to 8.4 ) & 0.043 \\
\hline \multicolumn{3}{|l|}{ Husband's education } \\
\hline Diploma & 0 & 0 \\
\hline Illiterate and primary school & $-5.1(-9.1$ to -1.1$)$ & 0.011 \\
\hline Secondary school & $-5.1(-8.2$ to -2.1$)$ & 0.001 \\
\hline High school & $-4.4(-8.4$ to -0.4$)$ & 0.028 \\
\hline University & $-3.0(-5.8$ to -0.1$)$ & 0.038 \\
\hline \multicolumn{3}{|l|}{ Economic condition } \\
\hline Almost satisfactory & 0 & 0 \\
\hline Satisfactory & 4.3 (2.0 to 6.6$)$ & $<0.001$ \\
\hline Unsatisfactory & $-12.0(-16.2$ to -7.9$)$ & $<0.001$ \\
\hline \multicolumn{3}{|c|}{ Pregnancy age at the time of labor } \\
\hline $34-40$ & 0 & 0 \\
\hline$<34$ & $-2.0(-8.5$ to 4.5$)$ & 0.549 \\
\hline$>40$ & $4.4(0.2$ to 8.7$)$ & 0.038 \\
\hline \multicolumn{3}{|l|}{ Number of labor } \\
\hline 1 & 0 & 0 \\
\hline 2 & $-11.8(-16.7$ to -6.9$)$ & $<0.001$ \\
\hline 3 & $10.7(-16.7$ to -4.6$)-$ & 0.001 \\
\hline$>3$ & $-10.1(-17.6$ to -2.5$)$ & 0.009 \\
\hline \multicolumn{3}{|l|}{ Tendency for pregnancy } \\
\hline Wanted & 0 & 0 \\
\hline Unwanted & $-5.1(-7.9$ to -2.3$)$ & $<0.001$ \\
\hline \multicolumn{3}{|l|}{ History of breastfeeding } \\
\hline No & 0 & 0 \\
\hline Yes & 10.0 (5.2 to 14.8$)$ & $<0.001$ \\
\hline Infant's age & 0.8 (0.1 to 1.5$)$ & 0.017 \\
\hline \multicolumn{3}{|l|}{ Receiving breastfeeding training } \\
\hline Yes & 0 & 0 \\
\hline No & $-3.2(-6.4$ to -0.1$)$ & 0.040 \\
\hline
\end{tabular}

have already been psychologically and mentally prepared, and thus have better QoL (24).

Our study showed that the number of children has an inverse correlation with QoL score, which is consistent with the study done by Akýn et al (18). In addition, low parity mothers are healthier and have higher QoL. In this study, the nulliparous women who received breastfeeding training or had older infants, had higher QoL than those with infant in neonatal period. This may be because the former group had already adjusted to the situation with time.

According to the findings of the present study, the QoL and breastfeeding can be improved through extensive planning and supportive measures by family and society. Due to the cross-sectional design of the study, as one of its limitations, the relationship between QoL and sociodemographic characteristics is not necessarily a causeand-effect relationship. The conduction of this study only on breastfeeding mothers with infants younger than 6 months was another limitation. This is because postpartum complications, such as depression, may also affect the QoL. Therefore, it is recommended that a similar study be performed after the period of exclusive breastfeeding (i.e. after the first 6 months of life).

\section{Conclusion}

Findings of this study show that the variables of age, spouse's age, spouse's education, economic status, gestational age at delivery, gravidity, tendency to pregnancy, history of breastfeeding, receiving breastfeeding training, and infant's age were predictors of QoL. Since sociodemographic variables can be moderated, the QoL and breastfeeding can be improved through extensive planning and supportive strategies by family and society.

\section{Conflict of Interests}

Authors declare that they have no conflict of interests.

\section{Ethical Issues}

The study was approved by the Ethics Committee of Tabriz University of Medical Sciences (TBZMED.REC. 1394.166).

\section{Financial Support}

The research deputy of Tabriz University of Medical Sciences supported the study.

\section{Acknowledgements}

This study was part of a master's thesis. We hereby express our gratitude to the research deputy of Tabriz University of Medical Sciences for their financial support for this research. We also thank all of the breastfeeding mothers who participated in this research as well as the staff of health centers in Falavarjan county, who aided us in conducting this research.

\section{References}

1. Guillon MS, Crocq MA, Bailey PE. the relationship between self-esteem and psychiatric disorders in adolescents. Eur Psychiatry. 2003;18(2):59-62. doi: 10.1016/S09249338(03)00002-6.

2. Mirghafourvand $M$, Mohammad-Alizadeh gharandabi S, Asghari Jafarabadi M, Tavananezhad N, Karkhaneh M. Predictor of health-related quality of life in iranian woman of reprodactive age. Appl Res Qual Life. 2015;10(3):723-37. 
doi: 10.1007/s11482-015-9392-0.

3. Bahadoran P, Alijanpoor M, Yousefy A. Relationship between infants' feeding pattern and mothers' physical and psychological health among the mothers covered by the health centers of Isfahan in 2013. Iran J Nurs Midwifery Res. 2015;20(2):216-220.

4. Zahed Pasha Y, Zahed Pasha E, Baleghi M. Islam and breastfeeding. Journal of Babol University of Medical Sciences. 2013;15(1):15-20. [Persian].

5. World Health Organization. Exclusive breastfeeding. http:// www.who.int/nutrition/topics/exclusive_breastfeeding/ en/. Accessed Feb 2014. Published 2014.

6. Dieterich CM, Felice JP, O'Sullivan E, Rasmussen KM. Breastfeeding and health outcomes for the mother-infant dyad. Pediatr Clin North Am. 2013;60(1):31-48. doi: 10.1016/j.pcl.2012.09.010.

7. Singhal A, Cole TJ, Lucas A. Early nutrition in preterm infants and later blood pressure: two cohorts after randomised trials. Lancet. 2001;357(9254):413-419. doi: 10.1016/S0140-6736(00)04004-6.

8. Sikorski J, Renfrew MJ, Pindoria S, Wade A. Support for breastfeeding mothers. Paediatr Perinat Epidemiol. 2002;17(1):407-417.

9. Shahla M, Katleen Fahy K, Ashley K, Kable AK. Factors that positively influence breastfeeding duration to 6 months; a literature review. Women Birth. 2010;23(4):135-145.

10. Blyth RJ, Creedy DK, Dennis CL, Moyle W, Pratt J, De Vries SM. Breastfeeding duration in an Australian population: the influence of modifiable antenatal factors. J Hum Lact. 2004;20(1):30-38. doi: 10.1177/0890334403261109.

11. Zubaran C, Foresti K. The correlation betweenbreastfeeding and maternal quality of life in southern Brazil. Breastfeed Med. 2011;6(1):25-30. doi: 10.1089/bfm.2010.0017.

12. Chen YC, Chie WC, Kuo SC, Lin YH, Lin SJ, Chen PC. The association between infant feeding pattern and mother's quality of life in Taiwan. Qual Life Res. 2007;16(8):12811288. doi: 10.1007/s11136-007-9233-1.

13. Alijanpoor M, Bahadoran P. Quality of life of nursing mothers referred to healthcare centers. Journal of Health and Care. 2015;17(2):108-115.

14. Jenny M, Fiona L, Fiona A. Public health interventions in midwifery: a systematic review of systematic reviews. BMC
Public Health. 2012;12:955. doi: 10.1186/1471-2458-12955.

15. Ghodsbin F, Yazdani KH, Jahanbin I. Impact of supportive efforts on the quality of lifeof primiparous women in the first six weeks after delivery. Iran J Obstet Gyneocol Infert. 2012;17(15):24-28. doi: 10.22038/ijogi.2012.5673.

16. Mirzayi H, Aghayari T, Katebi M. Quality of life of women within the family. Sociology of Social Institutions. 2014;1(3):71-93.

17. Baghaei M, Rahimi S, AdibM, Kazemnejad Leili E, Monfared A. Predictive personal factors of quality of life in hemodialysis patients. Nursing and Midwifery Holistic. 2013;24(74):9-19.

18. Akýn B, Ege E, Koçodlu D, Demirören N, Yýlmaz S. Quality of life and related factors in women, aged 15-49 in the 12-month post-partum period in Turkey . J Obstet Gynaecol Res. 2009;35(1):86-93. doi: 10.1111/j.14470756.2 008.00870.x.

19. Petrucci GD, Victora CG, Barros FC. Maternal nutriti on and duration of breastfeeding in birth cohort in Pelota. Brazil Revista de Saude Publica. 2000;34(3):259-265.

20. Scott RS. Essentials of Maternity, Newborn and Woman's Health Nursing. 6th ed. Philadelphia: Lippincott Williams \& Wilkins; 2007.

21. Lopes AA, Jennifer L, Gresham B, David A, Fukuhara S. factors associated with health-relatedquality of life among hemodialysis patients in the DOPPS. Qual Life Res. 2007;16(6):545-557. doi: 10.1007/s11. 136-006-9143-7.

22. Pakpour AH, Yekaninejad MS, Molsted S, Harrison AP, Hashemi F. Translation, cultural adaptation assessment and both validity and reliability testing of the Kidney Disease Quality of Life-Short Form version 1.3 foruse with Iranian patients. Nephrology. 2011;16(1):106-112. doi: 10.1111/j.1440-1797.2010.01389.x.

23. Abedi P, Jorfi M, Afshari P. Evaluation of the health promotion lifestyle and its related factors in reproductive aged women in Ahvaz, Iran. Community Health Journal. 2016;9(1):68-74.

24. McCarter-Spaulding DE, Kearney MH. Parenting selfefficacy and perception of insufficient breast milk. J Obstet Gynecol Neonatal Nurs. 2001;30(5):515-22.

Copyright $\odot 2018$ The Author (s); This is an open-access article distributed under the terms of the Creative Commons Attribution License (http://creativecommons.org/licenses/by/4.0), which permits unrestricted use, distribution, and reproduction in any medium, provided the original work is properly cited. 